\title{
28 Research Square \\ VES-13 Role to Identify Limited Life Expectancy in Older Adults in Primary Care Settings
}

\author{
Danilo Lopes Assis ( $\square$ nilomed.dla@gmail.com ) \\ Universidade Federal de Goias \\ Virginia Oliveira Chagas \\ Universidade Federal de Goias \\ Helton Saulo Bezerra dos Santos \\ Universidade de Brasilia \\ Cláudia Kimie Suemoto \\ Universidade de Sao Paulo \\ Alfredo Nicodemos Cruz Santana \\ Escola Superior de Ciencias da Saude
}

Research article

Keywords: Aged, Frailty, Screening, Sensitivity, Specificity, Primary Health Care

Posted Date: October 7th, 2019

DOl: https://doi.org/10.21203/rs.2.15655/v1

License: (우 This work is licensed under a Creative Commons Attribution 4.0 International License. Read Full License 


\section{Abstract}

Background: Population aging is a phenomenon that represents a challenge to the health systems, especially to settings with limited economic resources. In this scenario, it is essential to perform adequate screening, diagnostic, and therapeutic approaches to reduce health vulnerability. To investigate, for the first time, the potential role of Vulnerable Elders Survey (VES-13) to identify older adults with Limited Life Expectancy (LLE) (defined as estimated 10-year mortality risk $\geq 50 \%$ ) in Primary Health Care (PHC) settings. Methods: This cross-sectional study was performed in all PHC units in Jatai (Brazil) from July to December 2018. The sample size of 407 elderly individuals was obtained considering an older population ( $\geq 60$ years old) of 10,853 , a $50 \%$ prevalence, a $5 \%$ margin of error, a $95 \%$ confidence level, and $10 \%$ of possible losses.

Participants answered a questionnaire about sociodemographic and clinical characteristics, including the VES-13 (a tool to identify health vulnerability) and the Suemoto index (an index to estimate 10-year mortality risk for community-dwelling older adults). We tested the association between LLE and VES-13, using multiple logistic regression analysis. In addition, we investigated the discrimination of the VES-13 in identifying individuals with LLE using the area under the receiver operator characteristic curve (AUROC). Results: The mean age was $68.9 \pm 6.6 y$, and $58 \%$ were women. The mean score of VES-13 was $2.0 \pm 2.2$, the mean score of Suemoto index was $31.5 \pm 21.1 \%$, and $17.2 \%$ had LLE. The VES-13 was associated with LLE $(O R=1.57 ; p=$ $<0.0001)$. Moreover, a VES-13 score $\geq 2$ points was able to discriminate LLE (AUROC $=0.764(95 \% \mathrm{Cl}=0.078-$ 0.820 ); sensitivity $81 \%$ ). Conclusion: VES-13was able to identify older adults with LLE in PHC settings. Thus, the VES-13 could play a role in detecting older adults that would not benefit from screening (e.g., colorectal cancer) and strict control of chronic diseases (e.g., diabetes). However, other longitudinal studies are needed to confirm the role of VES-13 in identifying older adults with LLE, before the VES-13 can be adopted in routine clinical practice decisions in PHC, since we used a prediction model to identify LLE.

\section{Background}

Population aging is a phenomenon that represents a big challenge to the health systems, especially to settings with limited economic resources. In this scenario, it is essential to perform adequate screening, diagnostic, and therapeutic approaches to reduce health vulnerability [1]. The health vulnerability can be evaluated through a specific questionnaire, named Vulnerable Elders Survey (VES-13) [2].

In the validation study, the VES- 13 detected $32 \%$ of older adults with health vulnerability, who showed an excessive risk of functional decline and mortality over a 2-year period [2]. In other studies, VES-13 also identified older adults that more frequently used health services, those with complications and mortality after traumatic injuries and after emergency abdominal surgery, as well as older adults with functional decline and increased risk of 5-year mortality [3]. More recently, a study showed a potential role of VES-13 to detect poor quality of life among older adults in Primary Health Care (PHC) settings [1].

Another important issue in $\mathrm{PHC}$ is estimating the long-term risk of mortality. Older adults with limited life expectancy (LLE), defined by a high risk of mortality ( $\geq 50 \%$ ) in 10 years, may not benefit from cancer screening (colorectal, breast and prostate), or be more prone to adverse outcomes from strict diabetes control [4-11]. Thus, it is important to detect these patients in PHC, to discuss this topic and possibly severe sources by avoiding unnecessary screening and aggressive treatment procedures [12]. 
Thus, prognostic indexes can help to identify older adults with LLE. In this scenario, the Suemoto index can have a potential role, considering that it was developed using data from 35,367 older people from five cohorts, including information from Brazil and Mexico4. Unfortunately, PHC centers in Brazil do not routinely calculate the Suemoto index. On the other hand, the VES-13 is routinely used in PHC centers, since its use is recommended by the Brazilian Ministry of Health [13]. Thus, we investigated the potential role of VES-13 to detect older adults with LLE (estimated 10-year mortality risk $\geq 50 \%$ calculated by the Suemoto index) in PHC settings in Brazil.

\section{Methods}

This was a cross-sectional study. The data collection occurred in all PHC units in the municipality of Jatai (Brazil) from July to December 2018. The sample size for this study was calculated considering the total elderly population ( $\geq 60$ years old) in Jatai ( $n=10,853$ ), a prevalence of $50 \%$, a margin of error of $5 \%$, and a confidence level of $95 \%$, similarly as described in previous studies $[1,14]$. Consequently, the estimated sample size consisted of 370 individuals. Finally, 10\% was added to compensate for possible missing information in the questionnaires. Therefore, the final sample size calculation comprised 407 older adults. Each participating PHC unit included the same number of individuals [15].

Regarding the eligibility criteria, we included adults aged 60 years or older. In addition, exclusion criteria consisted of being assisted in PHC for less than 12 months, residing in the rural area and having cognitive impairment [defined as a score $\leq 5$ in the 10-point cognitive screener (10-CS)]. These exclusion criteria were chosen because we considered it is important to have been adequately assisted at a PHC center for a certain period of time to assure the collection of reliable information; significant cognitive impairment causes problems on self-reported data; and rural and urban areas have different characteristics, and approximately $85 \%$ of elderly adults live in urban areas [16-18].

Patients received information about this study, and the ones who agreed to participate and met the eligibility criteria signed the informed consent form.

Trained researchers contacted the patients while they were waiting for medical consultation, vaccination, wound care, or other health services in the PHC unit $[1,14]$. Interviews were carried out in a standardized manner using a questionnaire based on previous elderly cohorts $[19,20]$. Regarding sociodemographic data, we collected information on age, sex, level of schooling (years of formal education), ethnicity (white, black, and others), and living arrangements (living alone or not). Regarding the health history, we collected information on self-reported hypertension, depression, and number of medications. In addition, cognitive impairment was evaluated by the 10-CS, a validated tool for Brazilian older adults [21].

Health vulnerability was measured using the VES-13 version that was validated to Brazilian Portuguese $[2,22]$. The VES-13 has 13 items with specific scores: age ( 1 point for $75-84$ years old; 3 points for $\geq 85$ years old), self-rated health status evaluation (1 point for bad or regular), physical activity limitations [1 point for too much difficulty (or unable) in performing each item, with a maximum score of 2 points. The items were bending, crouching or kneeling; lifting or carrying objects weighing approximately 5 kilograms; raising or extending arms above shoulder level; handling and holding small objects; walking 400 meters; doing heavy 
house work such as scrubbing floors or cleaning windows], limitations for basic and instrumental activities of daily life (4 point for difficulty in performing one or more item, with a maximum score of 4 points. The items were buying personal items; dealing with money; walking through the room; performing light housework; taking a shower or bath). Consequently, the possible VES-13 scores vary from 0 to 10 , with higher scores associated with more health vulnerability. Older adults with scores of 3 or more are classically classified as vulnerable [6]. However, we used the VES-13 as a continuous variable (from 0 to 10 ) in this study.

The estimated limited life expectancy in 10 years was based on Suemoto index. This index predicts the mortality risk in 10 years for community-dwelling older adults. It uses information on age, sex, self-reported diabetes, heart disease, lung disease, cancer, smoking status, alcohol use, body mass index, physical activity, difficulty with bathing or showering, difficulty with walking several blocks, today's date correctly reported, and self-reported health status [4]. This index reports a predicted mortality in 10 years that varies from 0 to $100 \%$, based on the effect size of each of these variables and mortality in the test cohort. We used the online calculator for the Suemoto index available at e-prognosis (https://eprognosis.ucsf.edu/suemoto.php). We considered that LLE was present when the predicted 10 -year mortality risk was $50 \%$ or more. The cutoff of $50 \%$ were previously used in another study related to cancer screening in older adults [12].

The Statistical analysis was performed. The numerical variables were presented as mean and standard deviations (SD), while categorical variables were expressed as absolute numbers and percentages. The dependent variable was LLE (predicted mortality risk $\geq 50 \%$ calculated by the Suemoto index). The independent variable was the VES-13 score (continuous variable). Missing data for these variables were not imputed. We compared participants according to the presence of LLE using chi-square test for categorical variables and unpaired t-test or Mann-Whitney test for numerical ones. To test the association between limited life expectancy and health vulnerability measured by the VES-13, we used logistic regression analysis adjusted for age, sex, ethnicity, and education. We calculated the area under the Receiver Operating Characteristic (AUROC) curve to determine the discrimination of the VES-13 in identifying individuals with LLE. Additionally, we determined the best VES-13 cutoff with the best accuracy to identify these individuals using the Youden index [23]. We used the Stata 15 software (College Station, TX: StataCorp LLC) for the statistical analysis. The alpha level was set at the $5 \%$ level.

\section{Results}

Four hundred and fifty older adults were assessed to enroll in this study. However, eight individuals refused to participate, and 35 were excluded due to low scores in the 10-CS. Consequently, the study included 407 individuals, in agreement with the sample size calculation. The number of participants with missing data for variable of interest were one Ethnicity and one Hypertension. The mean age was $68.9 \pm 6.6 y 0,58 \%$ were women, $60 \%$ were non-Caucasian, the mean level of education was $3.6 \pm 3.7$ years, $19 \%$ lived alone, $71 \%$ had hypertension, $29 \%$ had depression, the mean number of medications was $3.2 \pm 2.1$. The mean score of VES13 was $2.0 \pm 2.2$. The mean predicted I0-year mortality by the Suemoto index was $31.5 \pm 21.1 \%$, and $17.2 \%$ had LLE (Suemoto index $\geq 50 \%$ ).

Sociodemographic and clinical data were compared according to LLE (Table 1). Participants with LLE according to the Suemoto index were older, more frequently males, and had fewer years of formal education 
than individuals without LLE.

Health vulnerability measured by the VES-13 was associated with LLE predicted by the Suemoto index (OR = $1.57,95 \% \mathrm{Cl}=1.31-1.64, \mathrm{p}<0.0001)$ (Table 2). The VES-13 showed a good discrimination to identify older adults with LLE (AUROC curve $=0.764,95 \% \mathrm{CI}=0.708-0.820$ ) (Figure 1). Regarding the VES-13 accuracy to detect LLE, the best cutoff of the VES-13 according to the Youden index was $\geq 2$, with a sensitivity of $81 \%$ and specificity of $57 \%$.

\section{Discussion}

The main finding of this study was showing, for the first time, that VES-13 was associated with LLE in older adults in PHC settings. In addition, the VES-13 showed a good discrimination to detect older adults with LLE according to the AUROC, and a cutoff point $\geq 2$ showed the best accuracy. The detection of patients with LLE is important, because these older adults should be advised to discontinue screening (such as colorectal, breast and prostate cancer) and to avoid strict control of chronic diseases (such as diabetes) due to the limited possibility of increasing survival and high risk of short-term complications [5-11]. These screenings and treatments have potential benefits only after many years of medical follow-up.

The VES-13 is already routinely used in the PHC setting in Brazil13. Consequently, primary care professionals could promptly use the VES-13 to detect older adults with LLE. Considering the specificity of the VES-13 score $\geq 2$ points was $57 \%$ to detect LLE, individuals with these VES-13 scores should be further evaluated by the Suemoto index to confirm LLE. At this point, it is important to emphasize that the use of two sequential test (as we propose the consecutive use of the VES-13 and Suemoto index to detect LLE) is frequently used in different heath scenarios, such as D-dimer testing and computed tomographic pulmonary angiography for pulmonary embolism detection [24]. However, future studies should use the VES-13 at baseline and investigate the ability of this tool to predict mortality after 10 years of follow-up.

Regarding the unnecessary cancer screening in older adults with LLE, one should consider the Case of Colorectal Cancer (CRC). CRC is one of the leading causes of cancer mortality, and screening has proven to reduce $\mathrm{CRC}$ mortality. Although $\mathrm{CRC}$ screening can bring benefits, older individuals should not have LLE, since this type of screening requires 10 years before 1 death related to CRC can be prevented among 1,000 screened individuals [12]. However, approximately $20-30 \%$ of individuals with LLE inappropriately undergo CRC screening [12,25]. Thus, it is very important to provide health professionals with prognosis information (such as LLE), so they can make the best clinical decisions. Furthermore, it is important to keep in mind that CRC screening is associated with a combined adverse event (gastrointestinal perforation or bleeding, cardiovascular events) rate of up to 12.3 per 1,000 screened individuals [26].

The personalized action plan for older adults with LLE in 10 years should go beyond the discussion about the unnecessary cancer screening and strict glycemic control. The primary care doctor should develop a collaborative work with geriatricians and gerontologists when treating patients with LLE. This collaborative care would analyze aspects that can be improved to maximize functional independence, quality of life and patient autonomy [1]. Finally, the primary care physician should refer older patients with high complexity to geriatric outpatient clinics [1]. 
Another important point in this study is to emphasize the use of VES-13 as a continuous variable, and not as

a categorical variable, as previously used ( $\geq 3$ as vulnerable; $<3$ as non-vulnerable). In three studies (including this one), mortality risk increased with each 1-point increment in the VES-13 score, corroborating the use of this score as a continuous variable $[6,28]$. In addition, scores $\geq 2$ in the VES -13 also detected poor quality of life in older adults in PHC [1].

Considering the external validity of this study, the characteristics of the older adults included in the present work were similar to those of previous studies $[1,14,27]$. Silva et al [1] included older adults with similar characteristics regarding age, sex, education level, and hypertension. The present study was also similar to another study using the VES-13, regarding age, sex, ethnicity, living arrangements, hypertension, and number of chronic medications1. Finally, in study also carried out with older adults in PHC, there were similarities regarding the frequencies of sex and depression, and in the age distribution [27].

This study should be considered regarding its limitations. First, it has a cross-sectional design, consequently VES-13 was associated with an LLE estimation, and not the actual 10-year mortality measured during a 10year period. However, estimated mortality or estimated adverse event rate is frequently used in clinical practice to decide treatments, as in studies that used the Schonberg index [12]. Another questionable point is the cutoff of $50 \%$ of mortality risk to define LLE. However, this cutoff was previously used to define LLE and to decide about cancer screening in older adults [12].

\section{Conclusion}

In conclusion, this is the first study to propose the use of VES-13 to identify older adults in the PHC settings with estimated LLE in 10 years. Older adults with VES-13 scores $\geq 2$ should be additionally evaluated through the Suemoto index to confirm the possibility of LLE. Individuals with LLE should receive personalized treatment, including the discussion about possible interruption of cancer screening and of aggressive control of chronic diseases. However, further longitudinal studies are needed to attain a better assessment of the role of VES-13 in detecting LLE in 10 years, before the VES-13 can be adopted in routine clinical practice decisions in the PHC setting.

\section{Abbreviations}

AUROC: Receiver Operating Characteristic; CRC: Case of Colorectal Cancer; LLE: Limited Life Expectancy; PHC: Primary Health Care; SD: Standard Deviations; VES-13: Vulnerable Elders Survey; 10-CS:10-point cognitive screener.

\section{Declarations}

\section{Acknowledgements}

Not applicable

\section{Funding}




\section{Availability of data and material}

The datasets generated and/or analysed during the current study are not publicly available due but are available from the corresponding author on reasonable request.

\section{Authors' contributions}

All of the authors participated in writing the manuscript. Data collection was performed by DLA; study design, ethical oversight, interpretation and critical revision of results was provided by DLA, VOC, HSBS, CKS and ANCS. All authors read and approved the final manuscript.

\section{Ethics approval and consent to participate}

The study was approved by the Research Ethics Committee of the Health Sciences Teaching and Research Foundation (Comitê de Ética em Pesquisa da Fundação de Ensino e Pesquisa em Ciências da Saúde FEPECS) (Protocol n².804.385/2018). For the research study, both written and verbal informed consent to participate in the study was obtained from all participants.

\section{Consent for publication}

Not applicable

\section{Competing interests}

The authors declare that they have no competing interests.

\section{References}

1. Silva SM, Santana ANC, Silva NNBD, Novaes MRCG. VES-13 and WHOQOL-bref cutoff points to detect quality of life in older adults in primary health care. Rev Saude Publica. 2019;53:26. https://doi.org/10.11606/S1518-8787.2019053000802.

2. Saliba D, Elliott M, Rubenstein LZ, Solomon DH, Young RT, Kamberg CJ, et al. The Vulnerable Elders Survey: a tool for identifying vulnerable older people in the community. J Am Geriatr Soc. 2001;49(12):1691-1699.

3. Min L, Yoon W, Mariano J, Wenger NS, Elliott MN, Kamberg C, et al. The vulnerable elders-13 survey predicts 5-year functional decline and mortality outcomes in older ambulatory care patients. J Am Geriatr Soc. 2009;57(11):2070-2076. https://doi.org/10.1111/j.1532-5415.2009.02497.x.

4. Suemoto CK, Ueda P, Beltrán-Sánchez H, Lebrão ML, Duarte YA, Wong R, et al. Development and validation of a 10-year mortality prediction model: meta-analysis of individual participant data from five 
cohorts of older adults in developed and developing countries. J Gerontol A Biol Sci Med Sci. 2017;72(3):410-416. https://doi.org/doi/10.1093/gerona/glw166.

5. Qaseem A, Denberg TD, Hopkins RH Jr, Humphrey LL, Levine J, Sweet DE, et al. Screening for colorectal cancer: a guidance statement from the American College of Physicians. Ann Intern Med. 2012;156(5):378-386. https://doi.org/10.7326/0003-4819-156-5-201203060-00010.

6. Qaseem A, Barry MJ, Denberg TD, Owens DK, Shekelle P. Screening for prostate cancer: a guidance statement from the Clinical Guidelines Committee of the American College of Physicians. Ann Intern Med. 2013;158(10):761-769. https://doi.org/10.7326/0003-4819-158-10-201305210-00633.

7. American Diabetes Association. Standards of medical care in diabetes-2014. Diabetes Care. 2014;37(suppl 1):S14-S80. https://doi.org/10.2337/dc14-S014.

8. Lee CH, Dershaw DD, Kopans D, Evans P, Monsees B, Monticciolo D, et al. Breast cancer screening with imaging: recommendations from the Society of Breast Imaging and the ACR on the use of mammography, breast MRI, breast ultrasound, and other technologies for the detection of clinically occult breast cancer. J Am Coll Radiol. 2010;7(1):18-27. https://doi.org/10.1016/j.jacr.2009.09.022.

9. Oeffinger KC, Fontham EH, Etzioni R, Herzig A, Michaelson JS, Shih YC, et al. Breast Cancer Screening for Women at Average Risk: 2015 Guideline Update from the American Cancer Society. JAMA. 2015;314(15):1599-1614. https://doi.org/10.1001/jama.2015.12783.

10. Royce TJ, Hendrix LH, Stokes WA, Allen IM, Chen RC. Cancer screening rates in individuals with different life expectancies. JAMA Intern Med. 2014;174(10):1558-1565. https://doi.org/10.1001/jamainternmed.2014.3895.

11. Abdollah F, Sun M, Sammon, JD, Choueiri TK, Menon M, Weissman JS, et al. Prevalence of nonrecommended screening for prostate cancer and breast cancer in the United States: A nationwide survey analysis. JAMA Oncol. 2016;2(4):543-645. http://dx.doi.org/10.1001/jamaoncol. 2015.5871.

12. Schonberg MA, Breslau ES, Hamel MB, Bellizzi KM, McCarthy EP. Colon cancer screening in U.S. adults aged 65 and older according to life expectancy and age. J Am Geriatr Soc. 2015;63(4):750-756. https://doi.org/10.1111/jgs.13335.

13. Ministério da Saúde (BR), Secretaria de Atenção à Saúde, Departamento de Atenção Especializada e Temática. Caderneta de saúde da pessoa idosa. 3.ed. Brasília (DF); 2014. Available from: http://bvsms.saude.gov.br/bvs/publicacoes/caderneta_saude_pessoa_idosa_3ed.pdf

14. Silva PA, Soares SM, Santos JF, Silva LB. Cut-off point for WHOQOL-bref as a measure of quality of life of older adults. Rev Saude Publica. 2014;48(3):390-397. https://doi.org/10.1590/S00348910.2014048004912.

15. Moreschi C, Rempel C, Siqueira DF, Backes DS, Pissaia LF, Grave MTQ. Family Health Strategies: Profile/quality of life of people with diabetes. Rev Bras Enferm. 2018;71(6):2899-2906. https://doi.org/10.1590/0034-7167-2018-0037.

16. Silva LB, Soares SM, Silva PAB, Santos JFG, Miranda LCV, Santos RM. Assessment of the quality of primary care for the elderly according to the Chronic Care Model. Rev Lat Am Enfermagem. 2018;26:e2987. https://doi.org/10.1590/1518-8345.2331.2987. 
17. Silva CSOE, Barbosa MMS, Pinho L, Figueiredo MFS, Amaral CO, Cunha FO, et al. Family health strategy: relevance to the functional capacity of older people. Rev Bras Enferm. 2018;71Suppl 2:740-746. https://doi.org/10.1590/0034-7167-2017-0078.

18. Garbaccio JL, Tonaco LAB, Estêvão WG, Barcelos BJ. Aging and quality of life of elderly people in rural areas. Rev Bras Enferm. 2018;71(Suppl 2):724-732. https://doi.org/10.1590/0034-7167-2017-0149.

19. Lebrão ML, Laurenti R. [Health, well-being and aging: the SABE study in São Paulo, Brazil]. Rev Bras Epidemiol. 2005;8(2):127-41. https://doi.org/10.1590/S1415-790X2005000200005.

20. Lima-Costa MF, de Andrade FB, Souza PRB, Neri AL, Duarte YAO, Castro-Costa E, et al. The Brazilian Longitudinal Study of Aging (ELSI-Brazil): objectives and design. Am J Epidemiol. 2018;187(7):13451353. https://doi.org/10.1093/aje/kwx387.

21. Apolinario D, Lichtenthaler DG, Magaldi RM, Soares AT, Busse AL, AmaralJR, et al. Using temporal orientation, category fluency, and word recall for detecting cognitive impairment: the 10-point cognitive screener(10-CS). Int J Geriatr Psychiatry. 2016;31(1):4-12. https://doi.org/10.1002/gps.4282.

22. Maia Fde O, Duarte YA, Secoli SR, Santos JL, Lebrão ML. [Cross-cultural adaptation of the Vulnerable Elders Survey-13 (VES-13): helping in the identification of vulnerable older people]. Rev Esc Enferm USP. 2012;46(SpecNo):116-22. https://doi.org/10.1590/S0080-62342012000700017.

23. Ruopp MD, Perkins NJ, Whitcomb BW, Schisterman EF. Youden Index and optimal cut-point estimated from observations affected by a lower limit of detection. Biom J. 2008;50(3):419-430. https://doi.org/10.1002/bimj.200710415.

24. Konstantinides SV, Torbicki A, Agnelli G, Danchin N, Fitzmaurice D, Galiè N, et al; Task Force for the Diagnosis and Management of Acute Pulmonary Embolism of the European Society of Cardiology (ESC). 2014 ESC guidelines on the diagnosis and management of acute pulmonary embolism. Eur Heart J. 2014;35(43):3033-3069. https://doi.org/10.1093/eurheartj/ehu283.

25. Mittal S, Lin YL, Tan A, Kuo YF, El-Serag HB, Goodwin JS. Limited life expectancy among a subgroup of medicare beneficiaries receiving screening colonoscopies. Clin Gastroenterol Hepatol. 2014;12(3):443450.e1. https://doi.org/10.1016/j.cgh.2013.08.021.

26. Warren JL, Klabunde CN, Mariotto AB, Meekins A, Topor M, Brown ML, et al. Adverse events after outpatient colonoscopy in the Medicare population. Ann Intern Med. 2009;150(12):849-857. https://doi.org/10.7326/0003-4819-150-12-200906160-00008.

27. Nogueira EL, Rubin LL, Giacobbo Sde S, Gomes I, Cataldo Neto A. Screening for depressive symptoms in older adults in the Family Health Strategy, Porto Alegre, Brazil. Rev Saude Publica. 2014;48(3):368-377. https://doi.org/10.1590/S0034-8910.2014048004660.

\section{Tables}

Table 1. Characteristics of the sample by limited life expectancy status* $(n=407)$ 


\begin{tabular}{|c|c|c|c|}
\hline & \multicolumn{2}{|c|}{ Limited Life Expectancy } & \multirow[t]{2}{*}{$\mathrm{p}$-va } \\
\hline & $\begin{array}{c}\text { No } \\
\mathrm{n}=337\end{array}$ & $\begin{array}{c}\mathrm{Ye} \\
\mathrm{n}=\end{array}$ & \\
\hline Age (years), mean (SD) ${ }^{\dagger}$ & $67.0(4.8)$ & $77.8(6.3)$ & $<0.0001$ \\
\hline Women, $\%^{\ddagger}$ & 60.5 & 45.7 & 0.02 \\
\hline Education (years), mean $(\mathrm{SD})^{\S}$ & $4.1(3.8)$ & $1.4(2.5)$ & $<0.0001$ \\
\hline Ethnicity, \% ${ }^{\ddagger}$ & & & 0.14 \\
\hline White & 39.2 & 41.4 & \\
\hline Black & 58.2 & 51.4 & \\
\hline Other & 2.7 & 7.1 & \\
\hline Living alone, \%‡ & 18.1 & 25.7 & 0.14 \\
\hline Hypertension, \% ${ }^{\ddagger}$ & 70.5 & 72.9 & 0.70 \\
\hline Depression, $\%^{\ddagger}$ & 29.4 & 28.6 & 0.89 \\
\hline Number of medications, mean( $\mathrm{S}$ & †3.1 (2.5) & $3.6(2.4)$ & 0.14 \\
\hline 10-CS score, mean (SD) ${ }^{\dagger}$ & $7.9(1.3)$ & $7.8(1.3)$ & 0.65 \\
\hline
\end{tabular}

*Limited life expectancy defined by 10 -year mortality risk $\geq 50 \%$ calculated by the Suemoto Index (J Gerontol A Biol Sci Med Sci. 2017;72(3):410-416).

${ }^{\dagger}$ unpaired t-test; ${ }^{\ddagger}$ chi-square test; ${ }^{\S}$ Mann-Whitney test.

Table 2. Association between limited life expectancy* and health vulnerability measured by the VES-13 $(\mathrm{n}=407)$

\begin{tabular}{lccc}
\hline & OR & 95\% CI & p \\
\hline Simple & 1.47 & $1.31-1.64$ & $<0.0001$ \\
Multiple $^{\dagger}$ & 1.57 & $1.28-1.92$ & $<0.0001$ \\
\hline
\end{tabular}

*Limited life expectancy defined by 10 -year mortality risk $\geq 50 \%$ calculated by the Suemoto Index (J Gerontol A Biol Sci Med Sci. 2017;72(3):410-416).

${ }^{\dagger}$ Logistic regression model adjusted for age, sex, ethnicity, and educational level

\section{Figures}




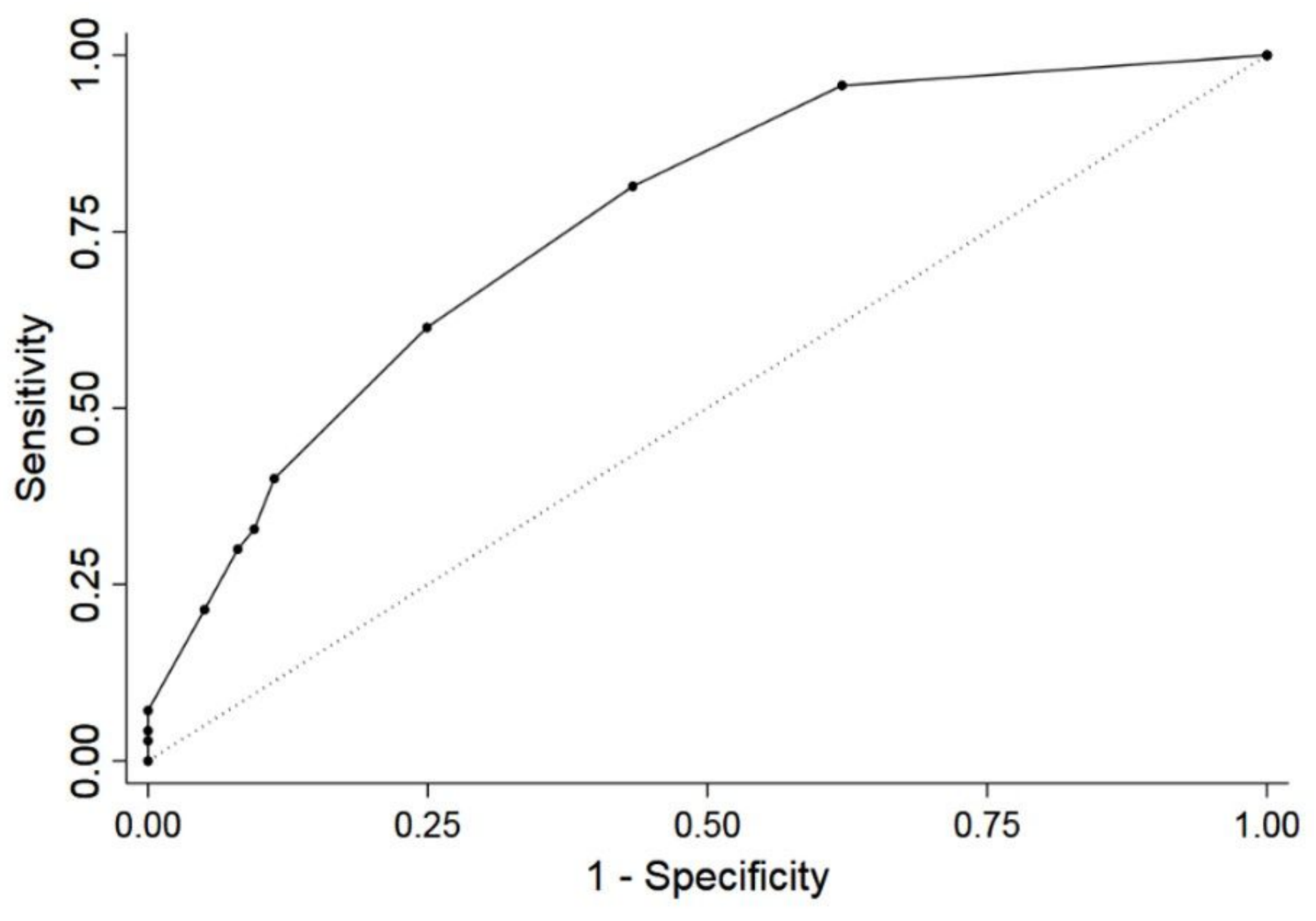

AUROC curve $=0.764(95 \% \mathrm{Cl}=0.708-0.820)$

Figure 1

Area under the receiver operator curve for the VES-13 to detect limited life expectancy $(n=407)$

\section{Supplementary Files}

This is a list of supplementary files associated with this preprint. Click to download.

- STROBEchecklistDanilo.doc 